\title{
Evaluation of elearning for the teaching of undergraduate ophthalmology at medical school: a randomised controlled crossover study
}

\author{
Caroline A. Petrarca ${ }^{1} \cdot J_{u l i a}$ Warner $^{2} \cdot$ Andrew Simpson $^{3} \cdot$ Robert Petrarca $^{3} \cdot$ Abdel Douiri $^{4,5} \cdot$ David Byrne $^{2} \cdot$ \\ Timothy L. Jackson (D) ${ }^{3}$
}

Received: 21 August 2017 / Revised: 1 February 2018 / Accepted: 3 February 2018 / Published online: 25 May 2018

(c) The Royal College of Ophthalmologists 2018

\begin{abstract}
Aim To compare ophthalmology teaching delivered by eLearning with traditional lectures, in terms of undergraduate performance and satisfaction.

Methods Randomised controlled crossover study at King's College London Medical School with 245 third year medical students. The ophthalmology syllabus was divided into ten topics. Five topics were randomised to be taught by traditional lectures and five by electronic learning (eLearning). For the second rotation of students the topics were crossed over, so that those topics taught by traditional lectures were taught by eLearning and vice versa. At the end of each rotation the students sat an optional online mock examination containing 100 questions (ten on each topic). Students' examination performance was compared between the two teaching methods. Student satisfaction was assessed using an online satisfaction survey. Outcome measures were the mean percentage of correct answers across all ten topics, student satisfaction and self-assessed knowledge.

Results The mean examination score for questions taught by eLearning was $58 \%$ (95\% CI, 55.7-59.6), versus 55\% (95\% CI 53.1-56.8) for traditional lectures $(P=0.047)$. Across all topics students were more satisfied with eLearning than traditional lectures, with $87 \%$ (95\% CI 84.5-88.4) rating eLearning as 'excellent' or 'good' versus 65\% (95\% CI 62.0-67.4) for lectures $(p<0.0001)$. Overall $180(75.6 \%)$ preferred eLearning compared to traditional lectures, with $166(69.7 \%)$ rating eLearning 'much better' or 'better,' 61 (25.6\%) 'neutral' and 11 (4.6\%) 'worse' or 'much worse.'

Conclusions Student satisfaction and examination performance are both enhanced by ophthalmology eLearning. Similar eLearning modules may be suitable for other specialties and postgraduate learning.
\end{abstract}

\section{Introduction}

There is substantial variation in ophthalmology teaching across medical schools, both in terms of the quantity of time allocated and the topics and clinical skills that are taught. A clinical ophthalmology placement is not mandated as part of UK undergraduate training and $21 \%$ of medical schools do not have a compulsory ophthalmology attachment [1]. Those that do provide a mean teaching duration of 7.6 days (range 3.5-15 days) [2].

The task force on undergraduate teaching in ophthalmology of the International Council of Ophthalmology compiled a core undergraduate ophthalmology curriculum covering clinical and taught topics [3]. It advised that ophthalmology teaching should involve classroom, clinic, and operating room experience, and students should be given the opportunity to observe simple clinical procedures. 
It was reported that no UK medical school covered all the recommended topics in their ophthalmology teaching curriculum [4]. Skills that would be considered essential in an accident and emergency (A\&E) department, such as fluorescein staining of the cornea, were taught in seven of the 18 schools, and three of 18 taught upper lid eversion, needed to exclude a subtarsal foreign body [4]. Another study reported that $56 \%$ of doctors were confident using an ophthalmoscope; the remaining $43 \%$ felt uneasy or very uneasy [5]. The authors also reported that $22 \%$ of the 130 primary care doctors they surveyed rated their undergraduate ophthalmology training as adequate. None of the doctors thought it was better than adequate [5].

A study at a London teaching hospital looked at the reliability of 67 emergency department referrals to ophthalmology from junior doctors and nurse practitioners. It found that only $36 \%$ of diagnoses by junior doctors were correct versus $75 \%$ of those by nurse practitioners $(p=$ 0.012) [6]. The accuracy of ophthalmology referrals was also assessed in Brisbane Australia. The referrals came from General Practitioners (GP), Emergency Department doctors and Optometrists. The study compared the initial diagnosis with that found by the Ophthalmology Department, and reported that the correct diagnosis was achieved by $35.9 \%$ of GPs, $41.9 \%$ of Emergency Department doctors and $48.2 \%$ of Optometrists [7]. A US study also reported that medical students and primary care physicians have insufficient knowledge of ocular anatomy, examination skills, common ocular problems and associations of systemic disease [8]. Taken together, these studies suggest that ophthalmology teaching at medical school should be expanded or improved.

Despite ophthalmology occupying only about $0.5 \%$ of a 5-year degree [3], 2.3\% of GP attendances are eye related, increasing to 6\% of Emergency Department attendances [6, 9]. Better ophthalmology education at medical school has the potential to improve the diagnosis and management of eye conditions, particularly for the doctors who do not undertake an ophthalmology attachment as part of their training. One obvious solution would be to increase the teaching time allotted to ophthalmology, at the expense of other specialties. Alternatively, the quality of the teaching might be improved or new ways of teaching explored; ideally ones that avoid competition for teaching time with other specialties.

Presently medical teaching in the UK is delivered by varying modalities and no one particular style dominates [10]. Common methods include lecturing, tutorials, practical teaching and problem-based learning. We aimed to explore electronic learning (eLearning) as a means of enhancing undergraduate ophthalmology teaching. This may enable increased exposure to ophthalmology, without needing to compete with other specialities for student time during office hours, experiential learning in clinic and theatre.

\section{Method}

The study ran at King's College London (KCL) medical school from January 2013 to July 2013 over two consecutive 12 week rotations. It involved 245 third year medical students.

\section{Ophthalmology syllabus topic randomisation and crossover}

The ophthalmology syllabus is taught in the third year of medical school and runs for 12 weeks, three times a year. The syllabus contains ten topics. The ten ophthalmology topics were randomly allocated to two groups (eLearning or lectures) in a 1:1 ratio, using an online randomisation service (www.random.org, Dublin, Ireland). For the first rotation of students five topics were taught by eLearning and five by didactic lectures. For the second rotation of students the topics were crossed over, so that those topics previously taught by eLearning were taught by didactic lectures and those delivered by didactic lectures were taught by eLearning (see Fig. 1).

eLearning was provided as an additional teaching opportunity (the volume of lecture material delivered did not change), and the topics rather than students were randomised. A Research Ethics Committee determined that an assessment of different teaching methods was better classified as a service evaluation, rather than a research project, and as such Research Ethics Committee review was not required [11]. Research Ethics Committee review was, however, required for student focus groups and a favourable opinion was obtained.

\section{Student focus group}

A student focus group was formed to help develop and test the eLearning material. Students were invited to participate in the focus group during the ophthalmology induction lecture. The objectives of the meeting were to help inform the design of the eLearning material, by exploring student preferences, and to invite them to share best practice from other specialties. The group also helped to determine an appropriate threshold in terms of the difficulty of mock examination questions.

\section{eLearning material}

The eLearning material was prepared for all ten topics to ensure uniformity across the syllabus and consistency of 


\section{Rotation 1}

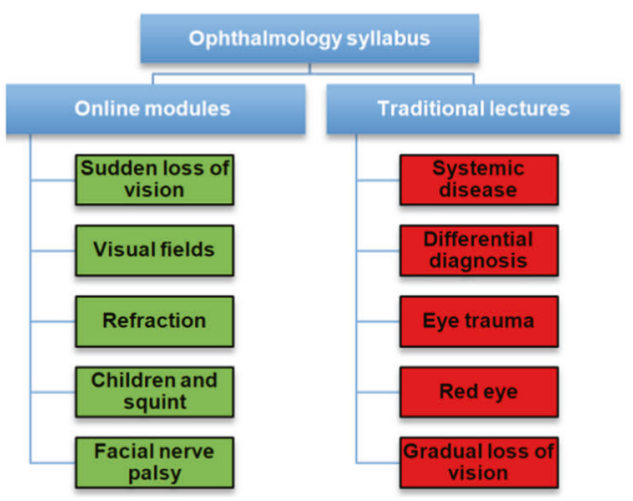

Rotation 2

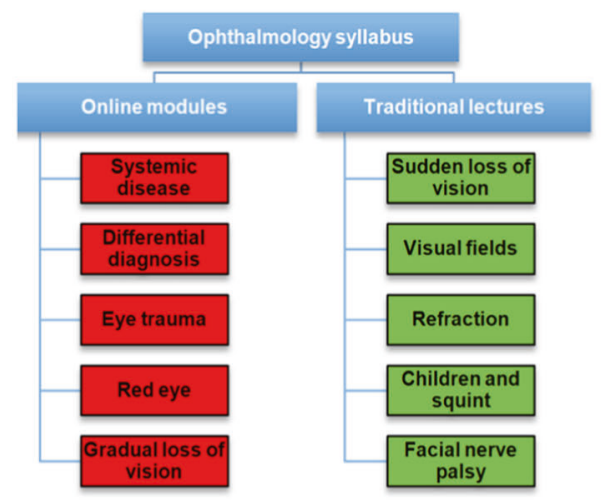

Fig. 1 The first rotation of students received five topics by eLearning and five different topics by didactic lectures. For the next rotation of students, the topics were switched so the previous learning lectures were now didactic and the didactic lectures were then eLearning

format and design. The writer was masked as to which of the five topics were to be allocated to eLearning and which to lectures. Each of the modules was designed to be completed in 40-60 min, equivalent to the time allocated to lectures. At the end of each module a self-assessment section was included, to consolidate students' learning and highlight areas that he or she may wish to revisit. The selfassessment questions were designed to be of a similar difficulty to those found in the end of year ophthalmology examination. The correct answers were subsequently given, along with an explanation. The eLearning modules were sent to the consultant ophthalmologists at Guys, King's and St Thomas's Hospitals (all part of the KCL Medical School). They were asked to review the modules within their subspecialty area of expertise; to identify errors, confirm that the coverage was appropriate, and ensure the information was up to date. The ophthalmologists were invited to suggest any more general changes that they felt would enhance the material. The eLearning material was delivered using the local online environment (The Virtual Campus) and assessment delivered using the university's
Virtual Learning Environment (MOODLE, Moodle Pty Ltd, Perth, Australia).

\section{Mock examination}

An independent ophthalmologist familiar with the clinical knowledge syllabus prepared 100 multiple choice examination questions to cover all ten topics. A total of 100 questions were chosen as this provided statistical power to detect a $1 \%$ difference in the results. The questions were designed to assess student performance, but also to serve as a revision tool prior to formal end of year examinations. The questions had up to five multiple choice answers, one of which was correct. The questions tested ophthalmic knowledge; they were not designed to assess practical skills. The examination writer was masked to topic allocation and did not have access to the eLearning material and or attend the lectures. The questions were reviewed by a consultant ophthalmologist and further checked by a member of the KCL Medical Finals Expert Panel. The eLearning module writer and lecturers did not have access to the questions.

\section{Didactic traditional lectures}

The topics randomised to didactic traditional lectures were delivered by consultant ophthalmologists in their area of expertise. As in previous years, the lectures were videoed and available on the virtual campus.

In the first term the eLearning modules were released the week after the lectures commenced, and the following term the eLearning modules were released the week before the lectures. In the last month of term students were invited to complete a mock examination and satisfaction survey, prior to term end. Students were provided with up to $3 \mathrm{~h}$ to complete the mock examination. Only the first complete attempt was recorded for the purposes of this study. All eLearning material (all ten topics) was subsequently released online, prior to final summative examinations.

\section{Student satisfaction survey}

An online survey was designed to assess student satisfaction with didactic lectures and eLearning. The survey was completed after the mock examination and prior to the student being able to access their mock exam score. The survey was designed to take $\sim 10 \mathrm{~min}$ to complete. All questions had mandated answers and the answers were either yes/no or required a rating from five options (such as excellent, good, neutral, fair or poor). Students who had not completed the mock examination and satisfaction survey were sent reminder emails at the end of a 1 month deadline. It was not compulsory for students to compete the exam or 
survey and they did not have to provide a reason for not participating.

\section{Statistical analysis}

The primary outcome was the mean percentage of correct answers across all ten topics, comparing eLearning with traditional lectures. The secondary outcome was the proportion of students preferring either eLearning or lectures. Other outcomes included the percentage of students rating learning as 'excellent' or 'good,' and the percentage rating eLearning as 'much better,' 'better,' 'neutral,' 'worse,' or 'much worse' than lectures. Unpaired $t$-tests and chi-squared tests were used to compare the two teaching methods in relation to the primary and secondary outcomes.

\section{Results}

There were 125 students in the first rotation and 120 in the second rotation. Of 245 students, $197(80.4 \%)$ completed the mock examination and $238(97.1 \%)$ completed the satisfaction survey. Of those completing the satisfaction survey, $46.6 \%$ were male and $53.3 \%$ were female. The proportion of male students was similar in each rotation (45.4 versus $47.9 \%)$. Lecture attendance was $110(88-92 \%)$ for both rotations of students.

The mean examination score for the topics taught by eLearning was $57.7 \%$ (95\% confidence interval (CI) [55.7-59.6]), versus 54.9\% (95\% CI [53.1-56.8]) for traditional lectures $(P=0.047)$.

Overall $180(75.6 \%)$ preferred eLearning and $58(24.4 \%)$ preferred lectures $(p<0.001)$. Further, $166(69.7 \%)$ students considered eLearning 'much better' or 'better' than lectures $(p<0.001)$; Fig. 2.

Considering all topics individually, students were more likely to rate a topic as 'excellent' or 'good' if it was taught

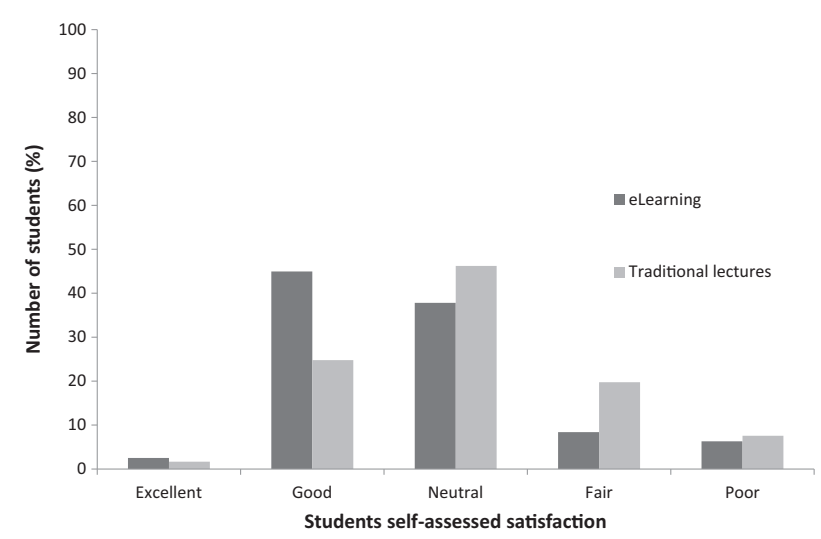

Fig. 2 Student perception of eLearning compared to lectures by eLearning than by traditional lectures $(86.7 \%$ (95\% CI [84.5-88.4]) versus $64.9 \%$ (95\% CI [62.0-67.4]); $p<$ 0.0001; Table 1).

Students' perception of their own knowledge is shown in Fig. 3. This suggests that students were more confident of their knowledge following eLearning.

Following an evaluation of these results, all ten eLearning topics were made available to future students.

\section{Discussion}

Our study assessed student performance and satisfaction with eLearning, in comparison with didactic lectures. We found that knowledge-based eLearning was associated with a small but highly significant advantage over lectures in terms of mock examination results, and much higher satisfaction ratings. For example, three-quarters of students preferred eLearning to traditional lectures.

Previous studies reported several advantages of eLearning, but we are not aware of a study comparing eLearning and traditional lectures in ophthalmology, or a randomised study in any medical specialty. It was reported that $67 \%$ of dental students preferred eLearning to didactic lectures [12]. Another study compared knowledge before and after eLearning and lectures in postgraduate occupational physicians. Both teaching methods significantly enhanced learning but the difference in knowledge between the teaching methods was not significant [13].

Students may see eLearning as complementing lectures rather than replacing them [14]. In a review of 300 studies of blended learning the results supported the use of online resources to supplement traditional learning [15]. It was reported medical students taught by blended learning were highly satisfied and had a statistically significant improvement in their performance in written examinations, clinical examinations and in clinical scenarios [16].

A potential risk of online resources is that they may reduce lecture attendance. However, one study found that recording lectures and posting these online did not impact on live lecture attendance [17]. Furthermore, students can view the lectures in their own time and work at their own speed. Information can be repeated as required. Supplementary eLearning may also increase exposure to a subject without competing with other specialties for time during office hours, with reduced scheduling pressure.

The eLearning modules appeared to be very acceptable to students with $95 \%$ grading them as 'excellent' or 'good.' To engage students and encourage a deeper understanding, additional learning material was included using call-out boxes and links to further material, sometimes with external links to quality-checked websites. This may provide a more dynamic learning experience, and means those students who 
Table 1 Students satisfaction ratings for each topic

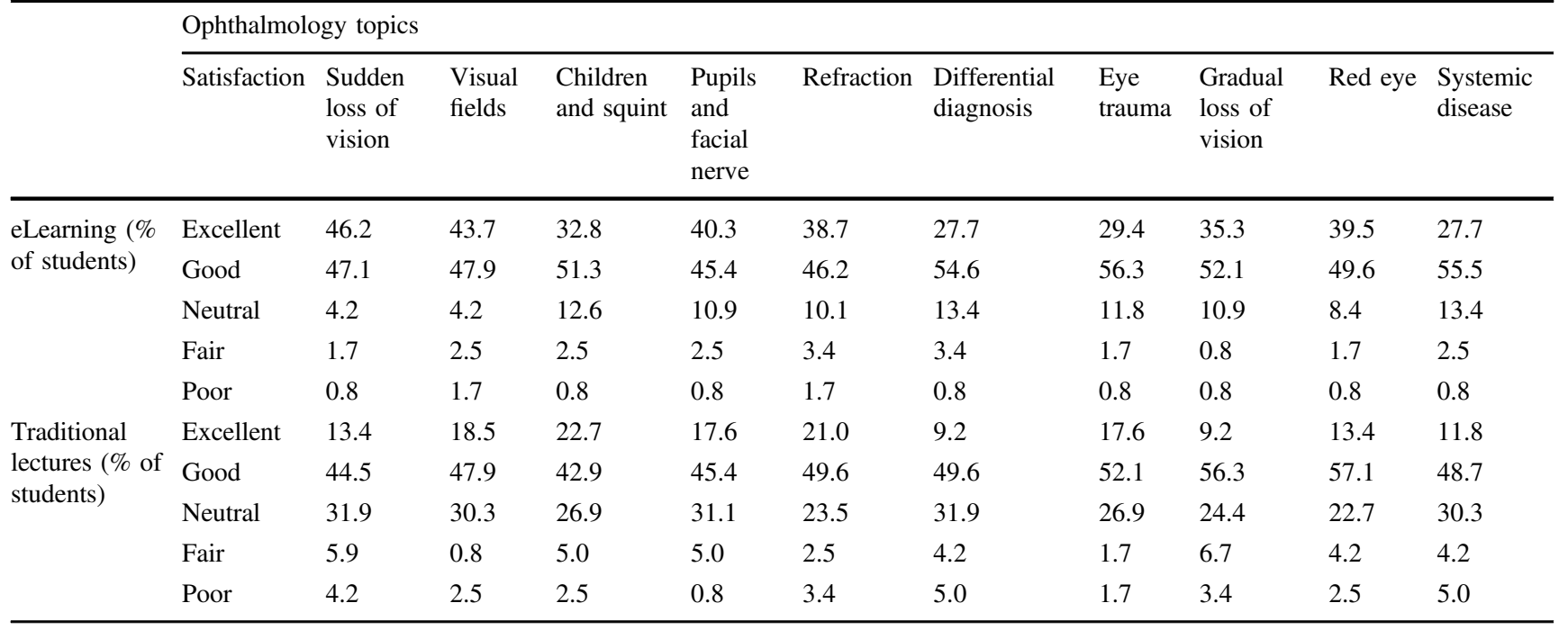

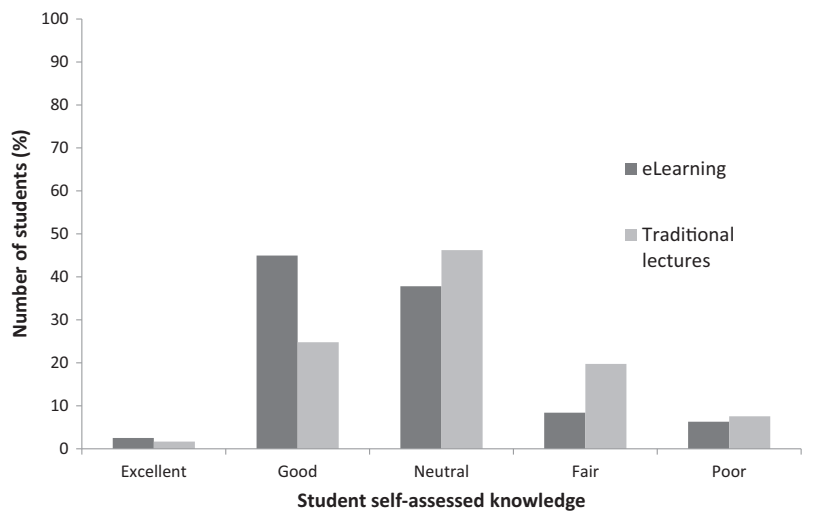

Fig. 3 How students rated their ocular disease knowledge after being taught by both teaching methods

wish to explore a topic beyond the syllabus are easily able to do so. The use of self-assessment also makes the learning more dynamic. Self-assessment can highlight weakness in a student's knowledge, and serves to consolidate learning. eLearning encourages independent learning and improves self-directed study [12]. Once created it is usually less expensive to deliver, and can be updated easily. eLearning has the potential to standardise teaching material to all students within an academic institution or nationally between medical schools. Lecture material may be harder to standardise and it is possible that the quality of our lecture material is not generalisable to all institutions. eLearning appears to be expanding. A 2010 report on online education in the USA found that the number of students taking at least one online course had increased by $21.1 \%$ from $~ 4.6$ to 5.6 million over just 1 year, the largest annual increase since records commenced in 2002 [18].

Disadvantages of eLearning include a reliance of students to be self-motivated and able to study independently [19]. However, only seven of our 245 students never accessed the online material. In comparison with small group problem-based learning there is less interaction with tutors and peers. Practical skills can be demonstrated, but eLearning does not circumvent the need for practice. It does not provide doctor-patient interaction, and may be poorly suited to teaching interpersonal and communication skills.

Weaknesses of this study include the fact that not all students completed the mock examination or satisfaction survey, although the response rates (80 and $97 \%$, respectively) compare favourably to many related studies. As the surveys were anonymised it was not possible to determine if those who failed to complete the surveys were different to those who did, hence bias cannot easily be excluded. We cannot exclude the possibility that some students may have recorded the eLearning modules in the first term and circulated these to students in the second rotation, but there was no evidence of this and had it occurred it would strengthen the result (as the lectures topics would also have been covered by eLearning). Key advantages of this study include its randomised, crossover design and relatively large sample size. The randomisation of topics rather than students also circumvented many potential ethical concerns, and may be appropriate for other educational studies. Future studies might consider if access to our eLearning material would benefit postgraduate doctors, such as those in A\&E departments or GPs.

In conclusion, undergraduate ophthalmology eLearning significantly improved student satisfaction and mock examination performance, and future studies may consider validating these findings in other specialties. 


\section{Summary}

\section{What was known before}

- Substantial variation in ophthalmology teaching across medical schools, both in terms of the quantity of time allocated and the topics and clinical skills that are taught. A clinical ophthalmology placement is not mandated as part of UK undergraduate training. Common teaching methods include lecturing, tutorials, practical teaching and problem-based learning.

\section{What this study adds}

- Topics taught by eLearning resulted in better results in a mock examination, with much higher satisfaction ratings, compared with didactic lectures.

- eLearning has the potential to standardise teaching material to all students within an academic institution or nationally between medical schools.

- A potential risk of online resources is a reduction in lecture attendance.

Acknowledgements This work forms part of a master in science degree at City University London (Caroline A. Petrarca). Abdel Douiri acknowledges the support by the NIHR Biomedical Research Centre based at Guy's and St. Thomas' NHS Foundation Trust and King's College London. The views expressed are those of the authors and not necessarily those of the NHS, the NIHR or the Department of Health.

\section{Compliance with ethical standards}

Conflict of interest All authors have completed the ICMJE uniform disclosure form at http://www.icmje.org/coi_disclosure.pdf and declare: no support from any organisation for the submitted work; no financial relationships with any organisations that might have an interest in the submitted work in the previous 3 years, no other relationships or activities that could appear to have influenced the submitted work

\section{References}

1. General Medical Council. Tomorrow's doctors: outcomes and standards for undergraduate medical education. 2009. http://www. gmc-uk.org. Accessed 11 Feb 2013.

2. Baylis O, Murray PI, Dayan M. Undergraduate ophthalmology education - a survey of UK medical schools. Med Teach. 2011;33:468-71.
3. Parrish RK, Tso MOM. Principles and guidelines of a curriculum for ophthalmic education of medical students: Presented by International Task Force on Ophthalmic Education of Medical Students - On behalf of the International Council of Ophthalmology (ICO). Klinische Monatsblatter fur Augenheilkunde. 2006;223(SUPPL. 5). https://doi.org/10.1055/s-2006-951844.

4. Welch S, Eckstein M. Ophthalmology teaching in medical schools: a survey in the UK. Br J Ophthalmol. 2011;95:748-49.

5. Shuttleworth GN, Marsh GW. How effective is undergraduate and postgraduate teaching in ophthalmology? Eye. 1997;11:744-50.

6. Ezra DG, Mellington F, Cugnoni H, Westcott M. Reliability of ophthalmic accident and emergency referrals: a new role for the emergency nurse practitioner? Emerg Med J. 2005;22: 696-99.

7. Statham MO, Sharma A, Pane AR. Misdiagnosis of acute eye diseases by primary health care providers: incidence and implications. Med J Aust. 2008;189:402-4.

8. Quillen DA, Harper RA, Haik BG. Medical student education in ophthalmology: crisis and opportunity. Ophthalmology. 2005;112:1867-8

9. McDonnell PJ. How do general practitioners manage eye disease in the community? Br J Ophthalmol. 1988;72:733-6.

10. Pugsley L, McCrorie P. Improving medical education: Improving patient care. Teach Teach Educ. 2007;23:314-22.

11. Brain J, Schofield J, Gerrish K, Mawson S, Mabbott I, Patel D, et al. Guide for clinical audit, research and service review. London: HQIP. 2009. http://www.hqip.org.uk/assets/Downloads/ Audit-Research-Service-Evaluation.pdf. Assessed July 2012.

12. Tan PL, Hay DB, Whaites E. Implementing e-learning in a radiological science course in dental education: a short-term longitudinal study. J Dent Educ. 2009;73:1202-12.

13. Hugenholtz NI, de Croon EM, Smits PB, van Dijk FJ, Nieuwenhuijsen $\mathrm{K}$. Effectiveness of e-learning in continuing medical education for occupational physicians. Occup Med. 2008;58: $370-2$.

14. Ruiz JG, Mintzer MJ, Leipzig RM. The impact of E-learning in medical education. Acad Med. 2006;81:207-12.

15. Sharpe R, Benfield G, Roberts G, Francis R. The undergraduate experience of blended e-learning: a review of UK literature and practice. Higher Education Academy (HEA); 2006. http://www. heacademy.ac.uk/research/Sharpe_Benfield_Roberts_Francis.pdf. Accessed 11 Feb 2013.

16. Makhdoom N, Khoshhal KI, Algaidi S, Heissam K, Zolaly MA. 'Blended learning' as an effective teaching and learning strategy in clinical medicine: a comparative cross-sectional universitybased study. J Taibah Univ Med Sci. 2013;8:12-17.

17. Larkin H. "But they won't come to lectures..." the impact of audio recorded lectures on student experience and attendance. Australas J Educ Technol. 2010;26:238-49.

18. Allen E, Seaman J. Class differences: online education in the United States. The Sloan Consortium; 2010. http://www.onlinelea rningsurvey.com/reports/class-differences.pdf. Accessed $11 \mathrm{Feb}$ 2013.

19. Pintz C, Posey L. Preparing students for graduate study: an eLearning approach. Nurse Educ Today. 2013;33:734-8. 